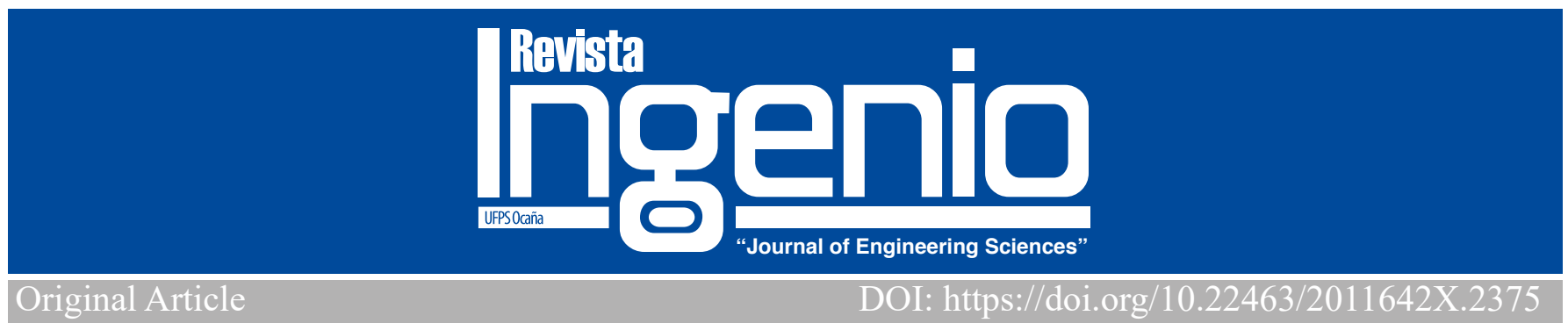

\title{
A study of DCT specimen in the verification of the influence of the geometric variation in the stress intensity factor
}

Estudio de una muestra de DCT en la verificación de la influencia de la variación geométrica en el factor de intensidad de tensión

\author{
MSc. Iago Freitas de Almeida ${ }^{1}$, DSc. Gelson de Sousa Alves², DSc. Nelson Afanador-García ${ }^{3}$
}

1University of Brasilia, Brazil,Orcid:https://orcid.org/0000-0002-8002-0591,Email: iago.freitas@hotmail.com, 170094511@aluno.unb.br

${ }^{2}$ Federal University of Piaui, Brazil, https://orcid.org/0000-0003-2007-2338,Email: gelson@ufpi.edu.br

${ }^{3}$ University Francisco of Paula Santander seccional Ocaña, Colombia, https://orcid.org/0000-0001-5463-2036, Email: nafanadorg@ufpso.edu.co

How to cite: I. F. Almeida, G. S. Alves \& N. Afanador "A study of DCT specimen in the verification of the influence of the geometric variation in the stress intensity factor", Revista Ingenio, 18 (1), pp. 10-16, 2021

\section{ABSTRACT}

Key words:

Concrete, Disk-shaped

Compact Tension

The objective of this work is to verify the influence of the geometric variation in the stress intensity factor in a linear elastic fracture mechanics model. The model consists in a Disk-shaped Compact Tension specimen (DCT) of concrete material. The methodology considers a comparative study of an analytical approach from the literature and numerical simulations. These numerical simulations

specimen, Fracture

Mechanics, Stress are performed in ANSYS Workbench program by the use of the Finite Element Method (FEM). The results show that the solutions obtained are satisfactory for the comparative study.

Intensity Factor.

\section{RESUMEN}

Palabras claves:

Hormigón, espécimen de prueba compacta de tensión en forma de disco,

Mecánica de fractura,

Factor de intensidad de

tensión.

\section{Introduction}

The occurrence of crack is one of the factors responsible for causing the loss of the material resistance capacity in structural engineering. This crack causes stress variations and must be considered in the elaboration of coefficients addressed in design codes. Thus, it is important to study the behavior that involves crack growth through fracture mechanics.

In Linear Elastic Fracture Mechanics (LEFM), several publications were developed to analyze the change in the behavior of stresses close to the cracks. These studies concluded that the stresses that occurred near the cracks were amplified following a relationship with the size of the crack, the applied stress and a geometric factor. The intensification factor was named as the stress intensity factor $(K)$, being related only to the type of material.

According to [1] studies were carried out for different materials and geometries to determine the equations of the shape factors and the $K$ of the materials. These factors can be obtained in an analytical-experimental way or by simulation using the Finite Element Method (FEM).

Some relevant publications in the area of fracture mechanics and in DCT specimen's analysis are [2-3-4-5-6]. In [2], DCT specimens were used to obtain experimental and numerical results. The results obtained were the maximum load and the total fracture energy. Thus, it can be seen the importance of the study of DCT in fracture mechanics. 
In this work, a three-dimensional study is considered to determine the stress intensity factor for pure Mode I. The model also considers a modification of some geometric parameters of the specimen. A numerical simulation is carried out by the use of software with formulation of FEM and the results were compared with analytical solutions based on the technical literature.

The work is organized in sections. This section presents the introduction. In section two, the stress approach is shown for LEFM. In section three, is presented the methodology to construct the models. The section four shows the results for analytical and numerical solutions. In section five, the conclusions are considered for both solutions.

\section{Stress approach of LEFM}

In Fracture mechanics, stress systems in the vicinity of crack tip can be approximated by three basic types of crack propagation [7]. These types of crack propagation correspond to rupture modes (Figure 1).

In Figure 1, the rupture Mode I corresponds to the stress resulted by the applied load in the normal plane of the crack surface. The Mode II corresponds to the friction shear mode where the stress acts parallel to the crack plane and perpendicular to the crack front. Mode III is also a shear mode; however, the acting stress is parallel to the crack plane and to the crack front.

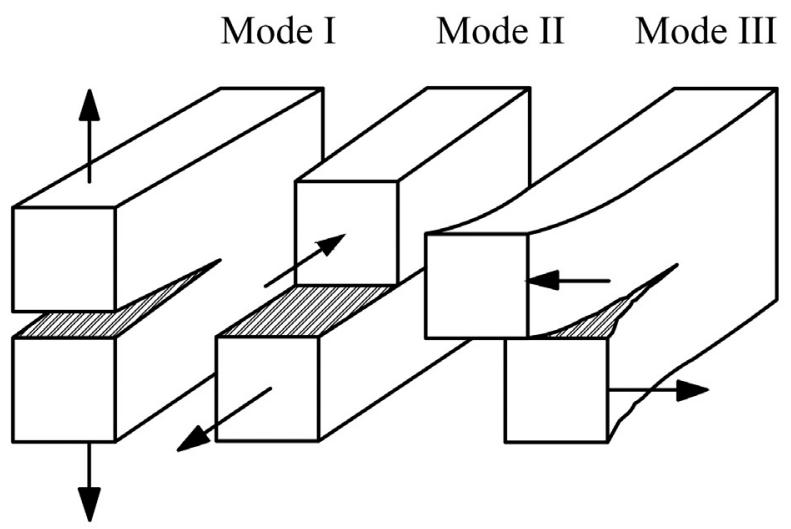

Figure 1. Rupture modes in fracture mechanics. Source. [8-9].

In the region close to the surface of the crack tip, there is amplification in the stress field and the stress magnitude is verified through the stress intensity factor $(K)$. In rupture Mode I, the stress intensity factor $K_{I}$ is fundamental for determining the stress fields and displacements in the region near the crack tip under the LEFM regime [8].

The stress intensity factor dependent of the stress field and is given by Equation (1) as:

$$
K_{I}=\frac{\sigma_{x x} \sqrt{2 \pi r}}{\left(\cos \left(\frac{\theta}{2}\right)\left[1-\sin \left(\frac{\theta}{2}\right) \sin \left(\frac{3 \theta}{2}\right)\right]\right)}
$$

in which, $\theta$ is an angle that represents the slope with the crack tip, $r$ is the distance between the analysis point and the crack tip, $\sigma_{x x}$ is the stress in the x-direction of the Cartesian stress components [8-10-11]. The stress intensity factor can also be formulated by Equations (2) and (3) as:

$$
K_{I}=\frac{\sigma_{y y} \sqrt{2 \pi r}}{\left(\cos \left(\frac{\theta}{2}\right)\left[1+\sin \left(\frac{\theta}{2}\right) \sin \left(\frac{3 \theta}{2}\right)\right]\right)}
$$

or

$$
K_{I}=\frac{\tau_{x y} \sqrt{2 \pi r}}{\left(\cos \left(\frac{\theta}{2}\right) \sin \left(\frac{\theta}{2}\right) \cos \left(\frac{3 \theta}{2}\right)\right)}
$$

in which, $\sigma_{y y}$ is the normal stress in the y-direction, $\tau_{x y}$ is the shear stress in the plane $x-y$ [8-10-11]. In the direction $z$, the stress $\sigma_{z z}=0$ for plane stress and $\sigma_{z z}=v\left(\sigma_{x x}+\sigma_{y y}\right)$ for plane strain with $v$ corresponding to the Poisson's ratio.

The Equations (1) to (3) can be reorganized considering the singularity field of the crack tip with $\theta=0$ [8]. In this case, the shear stress has zero value $\left(\tau_{x y}=0\right)$ and the normal stresses in the $x$ and y directions are given by Equations (4) and (5) as:

$$
\sigma_{x x}=\sigma_{y y}=\sigma=\frac{K_{I}}{\sqrt{2 \pi r}}
$$

and

$$
K_{I}=\sigma \sqrt{2 \pi r}
$$

The stress intensity factor formulation can be modified to consider the edge effect [8-10]. This modification consists in a geometric factor. In [8] and [11], is presented different expressions for the determination of geometric factors that take into account the different geometries of specimens used in experimental tests. Among the specimens, this research will address the Disk-shaped Compact Tension specimen (DCT), as this type of geometry is easily found in the literature and his geometric factor is given by Equation (6):

$$
f(a / W)=\frac{\left(2+\frac{a}{W}\right)}{\left(1-\frac{a}{W}\right)^{3 / 2}}(0.76+r(a / W))
$$

in which, $a$ is the notch size and $W$ is a characteristic dimension of the specimen. The function $r(\mathrm{a} / W)=4.8(\mathrm{a} /$ $W)-11.58(a / W)^{2}+11.43(a / W)^{3}-4.08(a / W)^{4}$. The stress intensity factor can be generically determined by Equation (7) as: 


$$
K_{I}=\sigma \sqrt{2 \pi r} f(\alpha)
$$

in which, $\alpha$ represents the $a / W$ ratio and $\sigma$ is the nominal stress.

\section{Methodology}

The specimen consists of concrete material with specified compression concrete strength $\left(f_{c k}=25 \mathrm{MPa}\right)$ and modulus of elasticity $(E=28 \mathrm{GPa})$. The methodology considered is shown in Figure 2.

The first step consists in the determination of the dimensions and characteristics of the DCT specimen (See Figure 2). In this step, is considered the determination of coefficient $\alpha$, adopting $\alpha=0.2 ; 0.4,0.6$ and 0.8 . Then, in the second step, an analytical evaluation of the stress intensity factor $\left(K_{I}\right)$ is considered with variation in the thickness $(B)$, geometric function $(f(\alpha))$ and in the crack (notch) length as a function of $\alpha$.

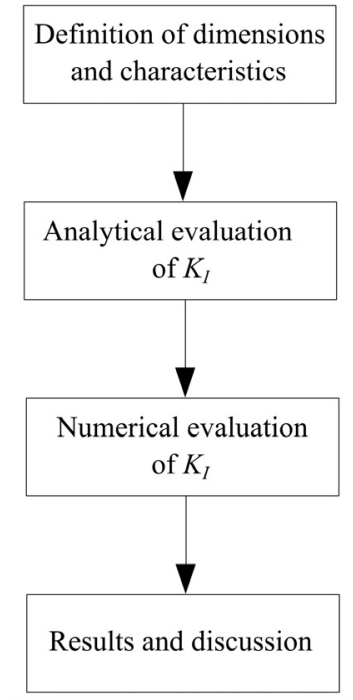

Figure 2. Flowchart of the methodology.

In Figure 2, the third step consists in the numerical evaluation of $K_{I}$. In this step, the ANSYS software is considered to be compared with the results of the previous step. Finally, in the last step, a discussion of the results is obtained.

The specimen has the characteristic dimension $(W)$, whose adopted value was equal to $110 \mathrm{~mm}$. Through the relationships of $\alpha$ and the defined dimension $W$, the notch sizes were determined to be equal to: $22 \mathrm{~mm}, 44 \mathrm{~mm}, 66$ $\mathrm{mm}$ and $88 \mathrm{~mm}$. The dimensions of the specimen were determined according to the characteristic dimension, as shown in Figure 3. The thickness values $(B)$ are equal to 51 $\mathrm{mm}, 102 \mathrm{~mm}$ and $204 \mathrm{~mm}$.

In the second step, or analytical evaluation, the geometric factor $f(\alpha)$ is established by Equation (6) and the load applied is $1000 \mathrm{~N}$ to each specimen with the respective thickness and notch size established in the previous step. The choice of the adopted load is based on references of the literature, being for this work based in the models of [9]. Then, the $K_{I}$ values are determined and several graphs were generated to evaluate the relation of $K_{I}$ with the variation of thickness, geometric function and variation of $\alpha$.

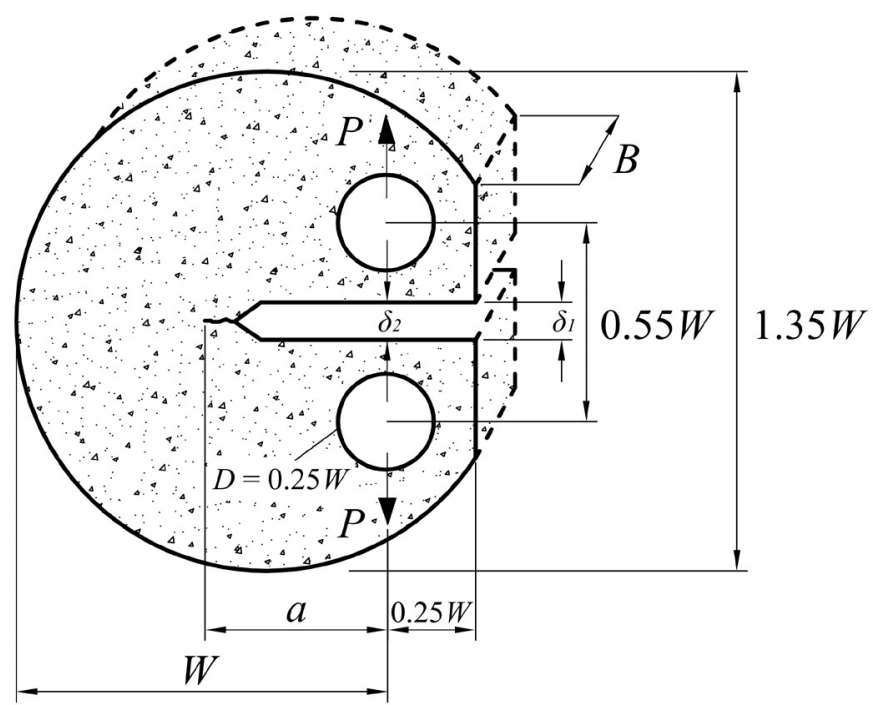

Figure 3. Standardized dimensions of the ASTM E399 [12] for DCT. Source. [11].

The numerical evaluation described in the third step was performed in the ANSYS software environment to determine the stress intensity factor. The mesh has a tetrahedral shape and the elements are constructed with a size of $5 \mathrm{~mm}$ for a good convergence of values because the difference in the results obtained with a more refined mesh has no significant magnitude, and therefore, there is no need to use a more refined mesh. The load is $1000 \mathrm{~N}$ and is applied on the internal surface of one of the holes. In this way, the other hole was restricted.

The $K_{I}$ calculation of numerical evaluation considered the use of integral $J$, having only been analyzed for the first contour, which is characterized as being the closest to the crack [10].

After calculate $K_{I}$ values for analytical and numerical solutions, graphs were generated. The $K_{I}$ is considered in relation of the thickness and the notch size. The conclusions are presented in the fourth step.

\section{Simulation model of DCT}

In this section, the results to the stress intensity factor, in pure Mode I, are presented by analytical solutions and Numerical simulations. 
In Figure 4 is shown the simulation discretization mesh considered in Ansys. The mesh is for $a=22 \mathrm{~mm}$ and $B=51$ $\mathrm{mm}$.

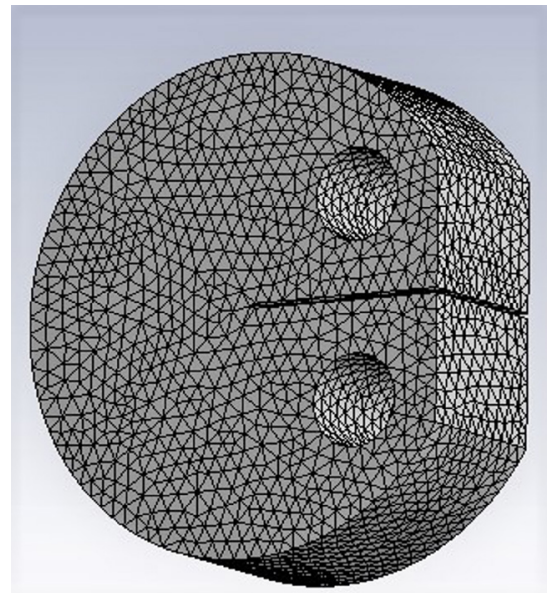

Figure 4. Simulation discretization mesh for $a=22 \mathrm{~mm}$ and $B=$ $51 \mathrm{~mm}$.

4.1 Analytical Simulation Model

In the first analysis, the influence of $K_{I}$ is verified in relation of the thickness $B$ for each notch size. Figure 5 shows the influence of these parameters.

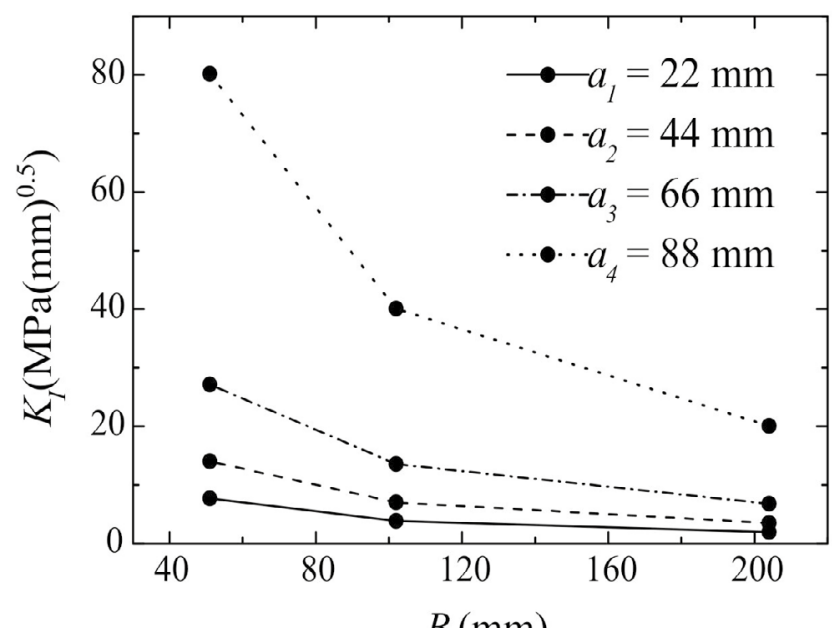

Figure 5. Influence of $K_{I}$ in relation to the thickness $B$ for different notch sizes simulated analytically.

In Figure 5, it can be noted that the $K_{I}$ magnitudes decreases with the increase of the thickness dimension for all notch sizes. Moreover, it is also concluded that if the notch size increases, the $K_{I}$ magnitude increases; highlighting the edge effect of notch $a_{4}$ with a discrepant difference in relation to the other notch sizes.

Figure 6 shows the relationship of $K_{I}$ with the geometric factor, which is a function of the coefficient $\alpha=(a / W)$.

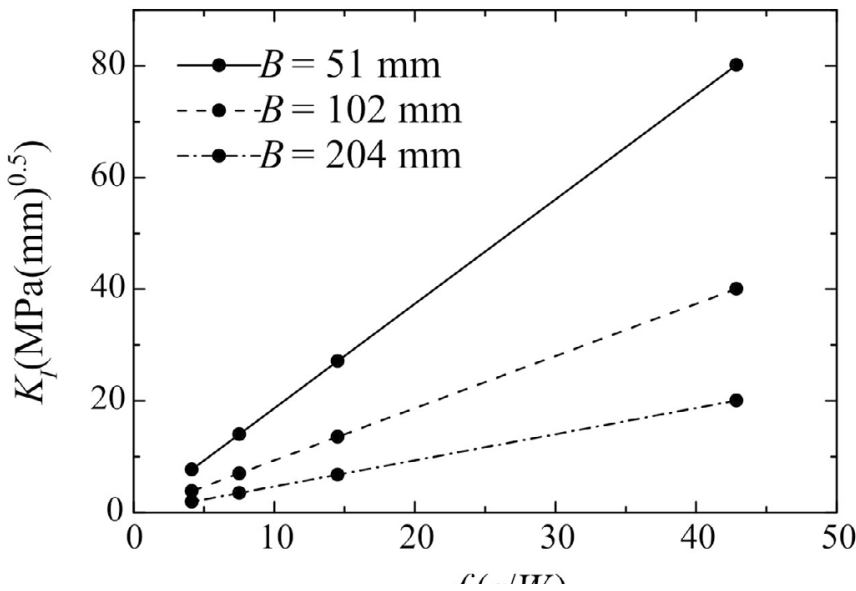

Figure 6. Influence of $K_{I}$ in relation to the geometric factor for different thicknesses.

In Figure 6, the $K_{I}$ value increases when the geometric factor increases. This increase is more pronounced for smaller thicknesses because of the inverse relationship in the analytical formulation. Figure 7 shows the $K_{I}$ relation with respect to $\alpha=(a / W)$ coefficient.

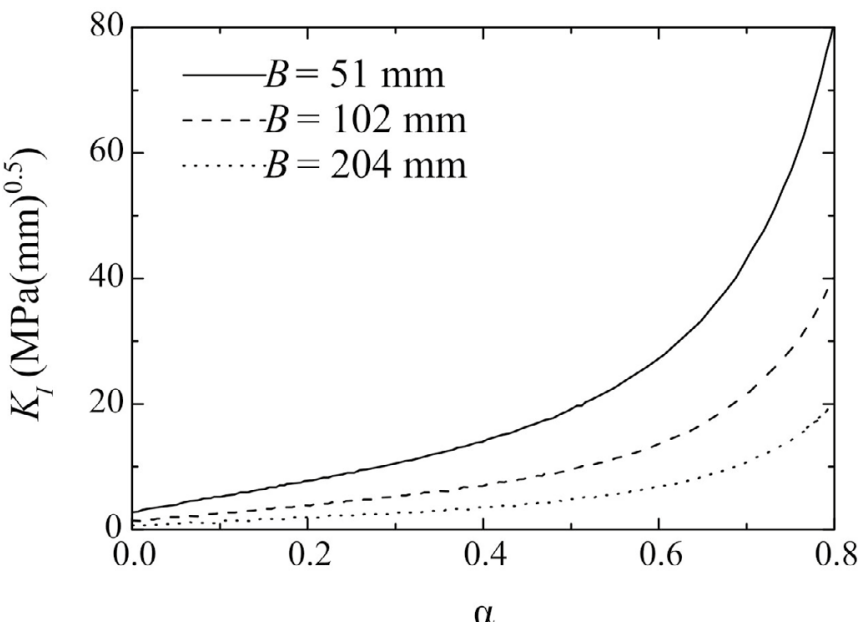

Figure 7. Influence of $K_{I}$ in relation to $\alpha$ coefficient for different thicknesses.

In Figure 7, the $K_{I}$ value increases with the increase of $\alpha$. The graph shows an exponential behavior occasioned by the geometric function that presents a fourth order polynomial. Moreover, it is also noted that, the highest $K_{I}$ values are related to the lowest thicknesses, as expected in Figure 7 and showed in Figure 6.

\subsection{Numerical Simulation Model}

This subsection presents the results of the numerical solution with a mesh convergence test.

4.2.1 Mesh Convergence test. The $K_{I}$ convergence test is performed in relation to the size of the element $\left(a_{e l}\right)$ and the 
results is shown in Figure 8. The model considers notch size $a=22 \mathrm{~mm}$ and a thickness $B=51 \mathrm{~mm}$.

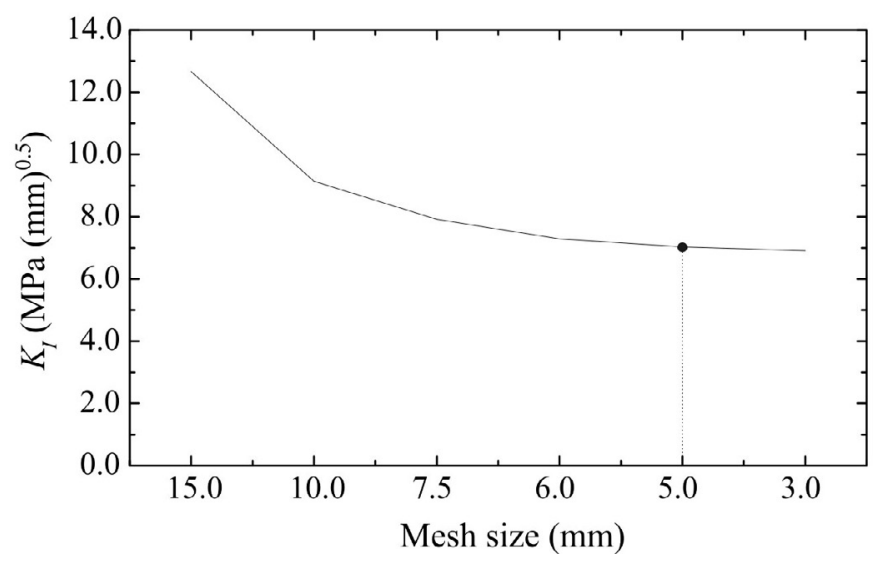

Figure 8. Mesh convergence test for $K_{I}$ calculation.

In Figure 8, six different sizes of elements were simulated for the convergence test, reducing the size of the element. The results show that the convergence of the results had been satisfactory for $K_{I}$ from an element size equal to $5 \mathrm{~mm}$. This element size is adopted for simulation of all examples.

4.2.2 Influence of $K_{I}$ for each notch size and different thicknesses. The analysis consists in verify the influence of $K_{I}$ to the four fixed notch sizes, in which for each size three different thicknesses were simulated. The results for $a=22$ $\mathrm{mm}$ is shown in Figure 9.

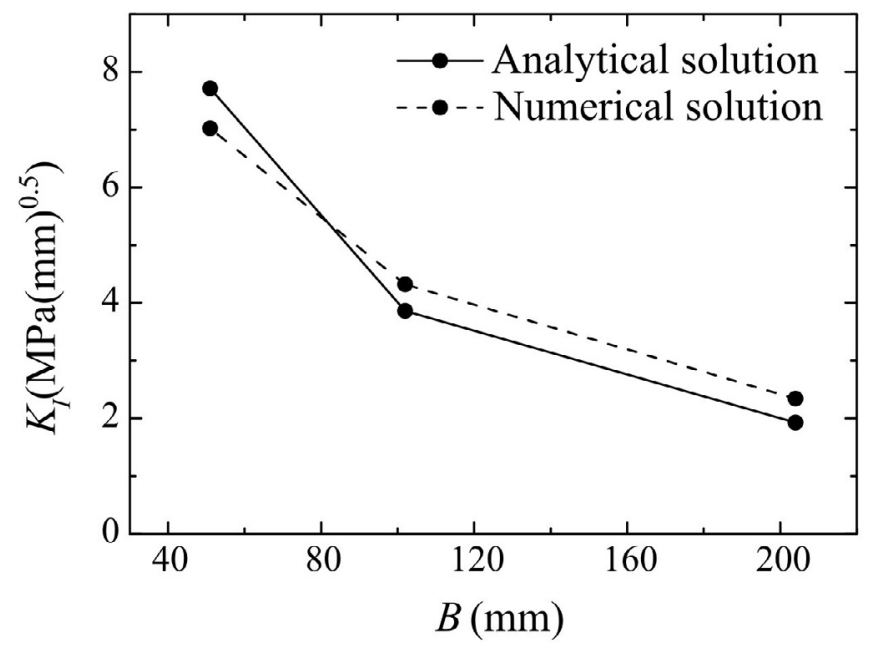

Figure 9. Influence of $K_{I}$ in relation to the thickness $B$ for $a=22$ $\mathrm{mm}$.

In Figure 9, the $K_{I}$ values are similar for both solutions. The results show that the $K_{I}$ magnitudes decreases when the thickness increases. The results for $a=44 \mathrm{~mm}$ is presented in Figure 10.

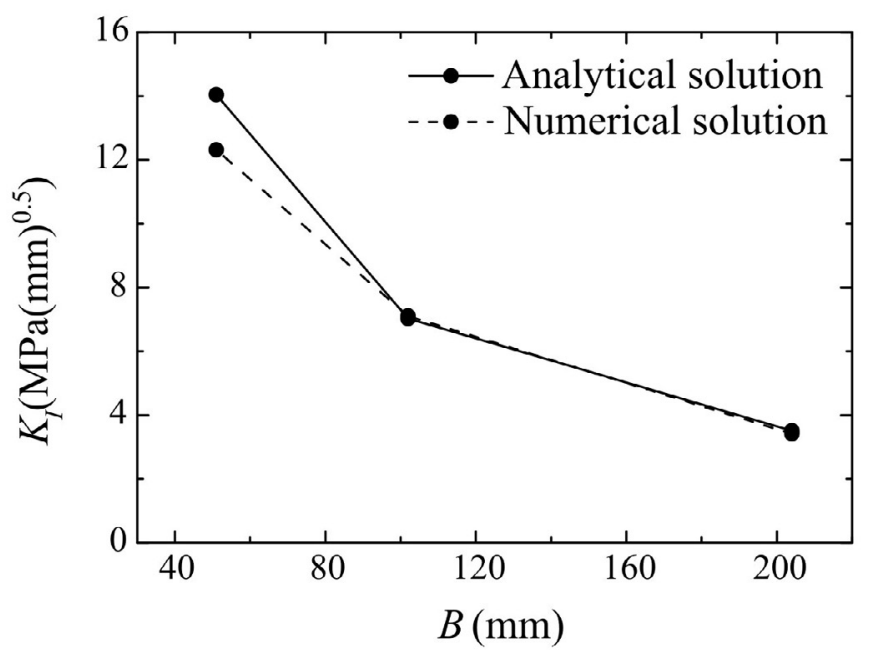

Figure 10. Influence of $K_{I}$ in relation to the thickness $B$ for $a=44$ $\mathrm{mm}$.

In Figure 10, the result of $B=51 \mathrm{~mm}$ shows a small difference of the analytical in relation to the numerical solution. However, this difference is insignificant. The results of $B=102 \mathrm{~mm}$ and $B=204 \mathrm{~mm}$ shows no difference of both solutions. The results of $a=66 \mathrm{~mm}$ is shown in Figure 11 .

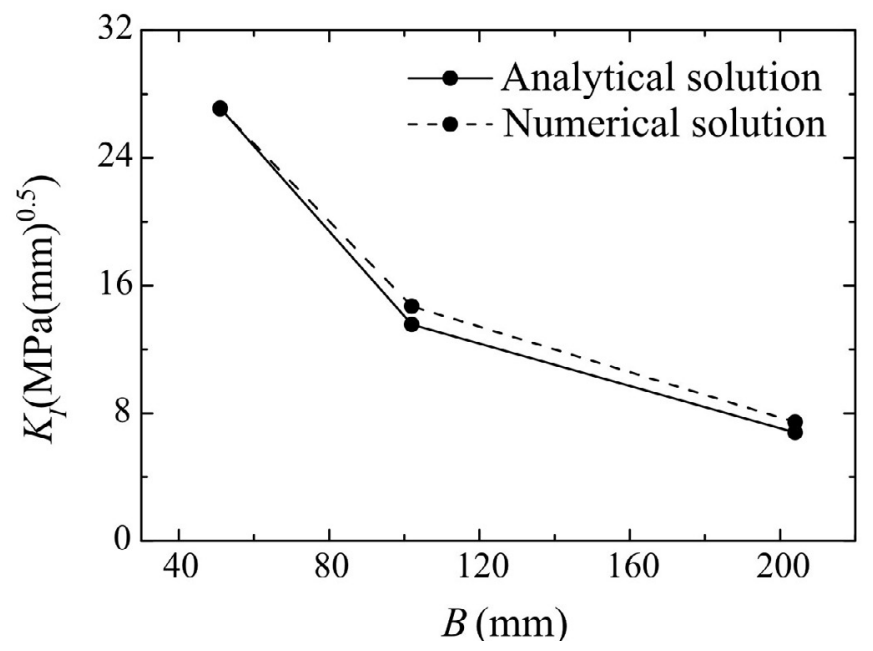

Figure 11. Influence of $K_{I}$ in relation to the thickness $B$ for $a=66$ $\mathrm{mm}$.

In Figure 11, the $K_{I}$ value decreases with the increase of the specimen thickness. The results of $a=88 \mathrm{~mm}$ is presented in Figure 12. 


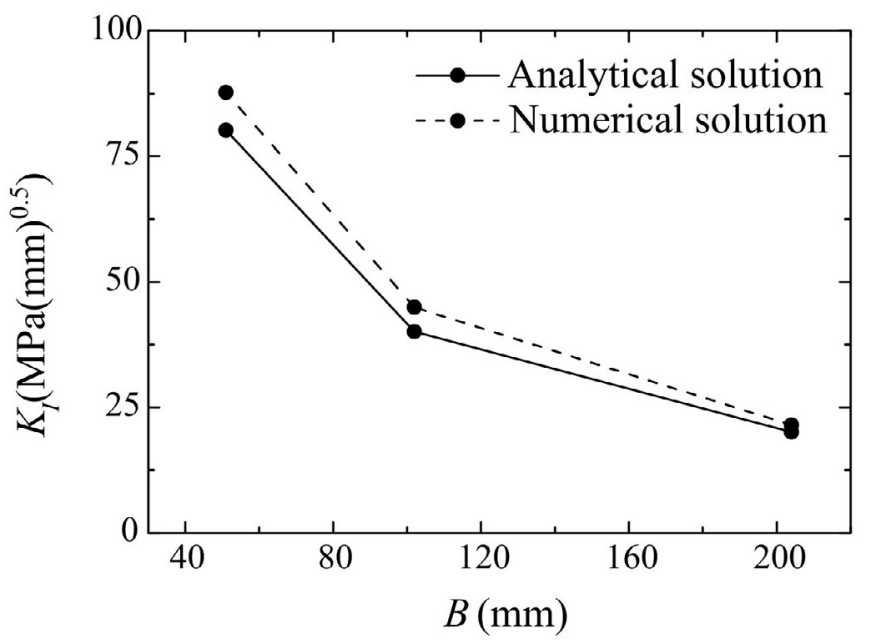

Figure 12. Influence of $K_{I}$ in relation to the thickness $B$ for $a=88$ $\mathrm{mm}$.

In Figure 12, the numerical simulation is practically similar to the analytical solution. Thus, the approximation obtained from the numerical simulation opens opportunities for later studies of more complex models.

4.2.3 Influence of KI for each thickness and different notch sizes. The second analysis consists in verify the influence of $K_{I}$ to the three sizes of fixed thickness $B$, in which for each thickness four different notch sizes were simulated (See Figure 13).

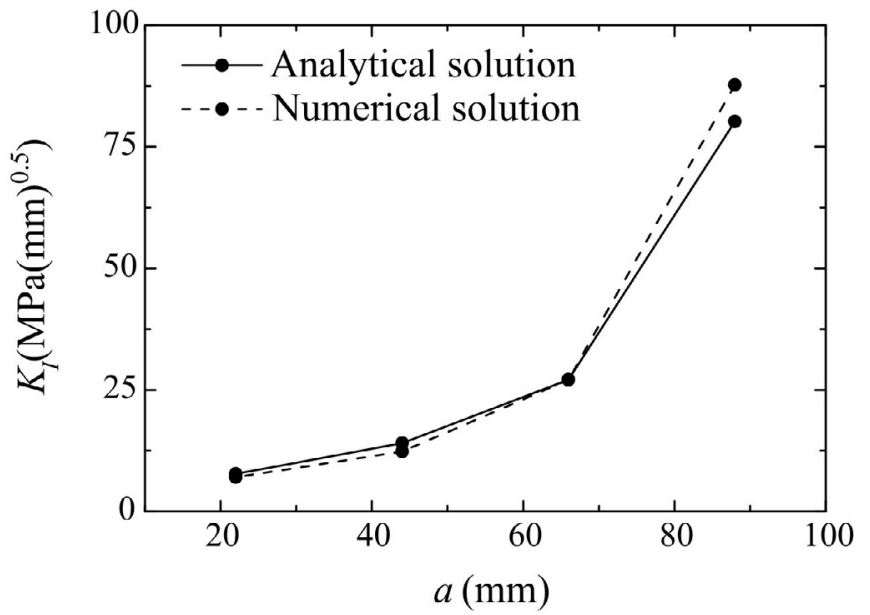

Figure 13. Influence of $K_{I}$ in relation to the notch size for $B=51$ $\mathrm{mm}$

In Figure 13, the $K_{I}$ magnitude increases with the increase of the crack notch for $B=51 \mathrm{~mm}$. The results of $B=102 \mathrm{~mm}$ is shown in Figure 14.

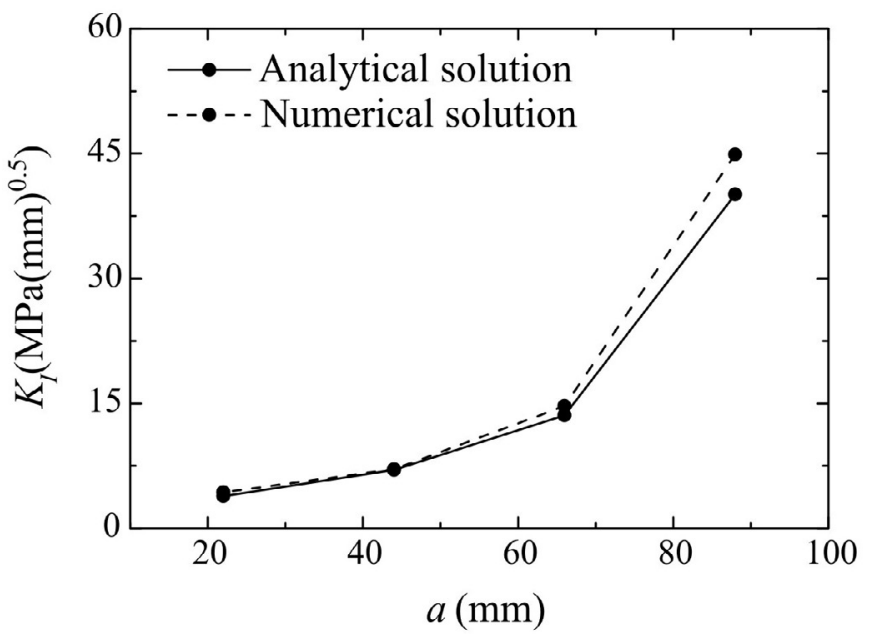

Figure 14. Influence of $K_{I}$ in relation to the notch size for $B=102$ $\mathrm{mm}$

In Figure 14, the results show a behavior similar to the Figure 13. The results for $B=204 \mathrm{~mm}$ is presented in Figure 15 .

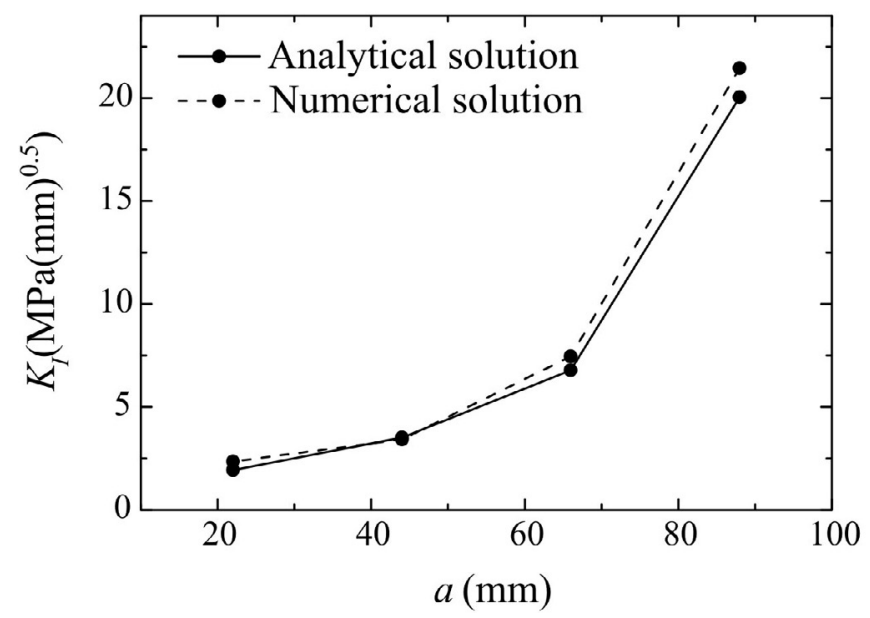

Figure 15. Influence of $K_{I}$ in relation to the notch size for $B=204$ $\mathrm{mm}$

In Figure 15, the $K_{I}$ value increases with the increase of the notch size. This effect happens because the singularity behavior occurs due to the reduction in the size of the ligament and the greater edge effect (this effect can also be noted in Figures 13 and 14).

\section{Conclusions}

The results showed that the numerical solution is efficient to reproduce values of $K_{I}$ for the DCT specimen. The $K_{I}$ value obtained satisfactory, coherent and convergent solutions with the theory studied and considered for this research.

In the numerical and analytical models it can also be concluded that the variation of the geometric dimensions influences the stress intensity factor. In this way, it can be 
noted that as the thickness increases, the intensity factor decreases. This decrease in the stress intensity factor is not linear, being necessary a future work to create a formulation to measure the behavior of the studied models.

In the study of the geometric factor, the behavior is different of the thickness variation. The increase of geometric factor generates also an increase in the stress intensity factor. However, when fixing the geometric factor, it is observed that the stress intensity factor decreases as the thickness increases.

In case of the notch size, it can be concluded that as the notch size increases for different sizes of thickness, the stress intensity factor also increases, as expected because the edge effect. This behavior is not linear and needs future work to verify and propose a formulation the represent the non-linearity.

\section{References}

[1] J. N. Reddy: An Introduction to the Finite Element Method. Singapore: McGraw-Hill, Second Edition, 1993.

[2] A. Amirkhanian, D. Spring, J. Roesler, K. Park, G. Paulino, "Disk-shaped Compact Tension Test for Plain Concrete", in T\&DI Congress, Integrated Transportation and Development for a Better Tomorrow, 2011, pp. 688-698.

[3] A. N. Amirkhanian, D. W. Spring, J. R. Roesler, G. H. Paulino, "Forward and Inverse Analysis of Concrete Fracture Using the Disk-Shaped Compact Tension Test", Journal of Testing and Evaluation, vol. 44, no. 1, pp. 625-634, January 2016, https://doi.org/10.1520/JTE20140312.

[4] J. Caicedo, A. Portela, "Direct computation of stress intensity factors in finite element method", European Journal of Computational Mechanics, vol. 26, no. 3, pp. 309-335, July 2017, http://dx. doi.org/10.1080/17797179.2017.1354578.

[5] J. Retama,A. G.Ayala, "Influence ofCrumb-Rubber in the Mechanical Response of Modified Portland Cement Concrete", Advances in Civil Engineering, vol. 2017, pp. 1-9, May 2017, https://doi.org/10.1155/2017/3040818.

[6] J. Yang, H. Lian, W. Liang, V. P. Nguyen, S. P. A. Bordas, "Model I cohesive zone models of different rank coals", International Journal of Rock Mechanics and Mining Sciences, vol. 115, pp. 145-156, March 2019, https://doi.org/10.1016/j. ijrmms.2019.01.001.

[7] M. Janssen, J. Zuidema, and R. J. H. Wanhill: Fracture Mechanics. New York: VSSD, Second Edition, 2006.
[8] T. L. Anderson: Fracture Mechanics - Fundamentals and applications. Boca Raton: CRC Press, Taylor \& Francis, Third edition, 2005.

[9] N. A. García. "Quantificação da Incerteza em modelos de fratura e fadiga utilizando polinômios de expansão de caos". PhD. dissertation, Department of Civil and Environmental Engineering, University of Brasília, Brasília, Brazil, 2019.

[10] R. J. Sanford: Principles of Fracture Mechanics. Upper Saddle River, NJ: Prentice Hall, 2003.

[11] H. Tada, P. C. Paris, and G. R. Irwin: The Stress Analysis of Cracks Handbook. New York: ASME Press, Third Edition, 2000.

[12] American Society for Testing and Materials (ASTM): E399 - Standard test method for linear-elastic plane-strain fracture toughness KIC of metallic materials. United States, 2009, pp. 1 33. 